\title{
Education Methods of Two-Child Family: Under the Mechanism of Sibling Relationship
}

\author{
Qiming Jia \\ School of Education, Tianjin University \\ Tianjin, China, 300350
}

\begin{abstract}
The proposal of two-child policy changed family structure and made it impossible to copy the previous education method. In order to put forward new scientific education methods, scholars need to track children's development process and explore related laws within the new family structure. This paper analyzes the roles of these mechanisms and their impact on children's growth. Then based on the mechanism of sibling relationship in the two-child family, we propose education suggestions for the two-child parents to give scientific family education.
\end{abstract}

Keywords-Two-child family; The status of family education; Family education methods; The mechanism of sibling relationship; Education advice

\section{ANALYSIS OF THE STATUS OF EDUCATION OF TWO-CHILD FAMILY}

In 2015, the policy that "A couple can have two children" was proposed in the Fifth Plenary Session of the 18th CPC Central Committee, and has attracted widespread attention from all walks of life. The majority of scholars discussed the impact of the implementation of the policy, and the first thing that affected was the family where the two children were. The birth of the second children breaks the balance of the original family. It is difficult for the first-born children, who are physically and mentally immature, to accept a new family member who will share parental resources with him. There are many reports on the first child's passive treatment of newborned brothers or sisters [1], therefore, how two-child parents scientifically educate their children and properly handle the sibling relationship is a major issue in China's current family education.

Since the reform and opening up, there have been breakthroughs in family education in our country, people's understanding of the general characteristics and laws of family education has been increasing, and the scientific nature of education methods has become increasingly important. However, the education of two-child families still has many problem in the new era. The following are the main performance.

Explicit knowledge is the knowledge that can be systematically expressed and effectively communicated to others. It is usually expressed by words or words. The explicit knowledge of the education methods mentioned in this article is the scientific and systematic knowledge of how two-child family to educate children [2]. Although before the single-child policy has been implemented, the family in our country is multi-child structure. We also has had many ways of teaching children, but now the social environment children faced is changing. At the same time, with the deepening of human exploration, people's understanding of the characteristics of children's physical and mental development and the law of change is also increasing. Therefore, parents' education methods must continue to innovate on the basis of inheriting the quintessence of their ancestors. Based on the fact that China has implemented the one-child policy for a long time, the laws governing the physical and psychological development of children in multiple children family have not yet been fully explored. The lack of knowledge of sibling relationships has prevented the form of the scientific and systematic method of family education.

Second, the lack of tacit knowledge of education methods Tacit knowledge is highly personal, which is difficult to express clearly and logically. It is people's unsystematic knowledge of experience. If explicit knowledge is the "tip of the iceberg" that reveals the surface of the water, then tacit knowledge is the majority of the icebergs that are hidden beneath the surface of the water [2].The acquisition of tacit knowledge does not depend on reading or lectures, but on personal experience. It comes from all the information that individual felt. At present, the parents of most young families in China are the single child. They do not have experience with their brothers and sisters in the family. Although there are peers or cousins of similar ages, there is no competing relationship for parental concerns between them. There is also no older children's responsibility for younger siblings or young children's worship and dependence for brother and sister. As a result, young parents are not able to know how the children feel when they face their brothers and sisters, and even less able to acquire the experience of educating their children in the process of growing up. This lack of tacit knowledge makes young two-child parents often overwhelmed by sudden events during daily life.

Third, the contradiction between the urgency of education needs and the lag of research. Family education has now entered an increasingly knowledgeable, professional, and technical stage [3]. With the deepen of family education research and the popularization of family education knowledge people pay more and more attention to the rightness of family education methods. They also hope to cultivate and educate their children in a scientific and democratic manner under the guidance of scientific theories. For children's physical and mental health, many young parents said that they would not blindly follow their parents' education methods, but would learn scientific education methods through courses or books. However, the two-child policy has just been implemented in 
recent years. The problems posed by the birth of the second child to family education have just surfaced. The research on such issues has just started and lack results. This makes parents facing difficulties unable to obtain scientific guidance. The contradiction between the urgency of education needs and the lag of research.

\section{THE MECHANISM OF THE SIBLING RELATIONSHIP}

The mechanism of the sibling relationship is how the sibling relationship affects the mental development and adaptation of children in this relationship [4]. Foreign studies have found that after controlling the influence of parents and friends, the sibling relationship still has an impact on the development of children [5-6]. Therefore, it is necessary to analyze and explore the mechanism of the sibling relationship.

\section{A. Attachment mechanism}

In the two-child family, children not only establish attachment relationships with their parents, but also establish attachment relationships with siblings [7]. If children establish the secure attachment relationship with their siblings, they will form a safe internal processing model, thus establishing a positive evaluation of themselves and the outside world, more confident, and better at dealing with interpersonal relationships. And the secure attachment relationship with siblings enables them to be confident that they will get support from their siblings when facing difficulties, thus prompting them to adapt the society actively [8]. Conversely, fail to establish the secure attachment relationship may lead to children's negative assessments of themselves and the world, lack of self-confidence, and having problems with interpersonal relationships, and thus fail to adapt society.

\section{B. Social learning mechanism}

According to Bandura's social learning theory, individuals learn the social behaviors, attitudes, and beliefs through observational imitation, and are more inclined to imitate people who close to them in all aspects [9]. Based on this theory, when interacting with the siblings, they will learn each other's personal affairs, interpersonal communication and emotional expression [10]. There are two kinds of results between the siblings through social learning. One is that the siblings learn good behavior through mutual support and reciprocity or imitate each other's adaptive activities; the other is that siblings acquire problem behaviors through fighting and conflict or imitating each other's bad activities [4]. At the same time, children will also decide whether to imitate the behavior by observing the result of their siblings' behavior. That is, children will more inclined to imitate the behavior which is rewarded.

\section{Social Comparing Mechanisms of siblings}

The mechanism of social comparison is that individuals evaluate themselves by comparing with others. This comparison will affect the individual's self-esteem. For the children of the two-child family, the siblings are their important comparisons, and the influence of comparision with their siblings is greater than the effect of comparisons with friends [11]. One important reason for sibling comparisons is that children perceive that parents have differences in their parenting investment, including material and spiritual input [12]. They all hope that they can get more care from their parents, and therefore treat each other as a competitor. Comparing between siblings will encourage children to change their way of life and play an important role in shaping their personality.

\section{EDUCATION SUGGESTIONS FOR SECOND-CHILD FAMILY UNDER THE MECHANISM OF SIBLING RELATIONS}

\section{A. Strengthen inter-personal interactions and establishing safe attachment relationships}

The formation of the secure attachment relationship depends on the benign interaction between siblings, and the formation of benign interaction requires the active guidance of parents. Because there is a competitive relationship among the siblings, if they are not properly guided, they may create hostility and lead to malignant relationship. First of all, for older children who are dominant in the interaction, parents should guide them to accept their younger siblings and strengthen their sense of responsibility for new identities. Parents need to do the following things: Firstly, parents should consciously construct children's positive knowledge of unborn siblings before the birth of their second child, and emphasize the positive impact that the fetus will have on children after they are born; Secondly, strengthen children's sense of responsibility for their younger siblings and deliberately assign tasks that are simple and easy for them to participate in taking care of the newborns. Through constant demands and guidance, let them internalize this kind of pay for themselves; thirdly, increase the time for siblings to get along, and help children establish mutual understanding and strengthen emotional connections through constant interaction. Furthermore, for young children who are passive in the interaction, parents should guid them to fully feel the goodwill behavior of older children and help them promote their fellowship in good interactions.

\section{B. Enhance relations, Adhering to principles, etting up a good social learning}

Siblings will learn each other's personal affairs, interpersonal relationships, and emotional expressions, especially for young children. Older children seem to be their role models. The first child's behavioral patterns and living habits will have an important impact on the second child. Therefore, a good education for the first child will have a multiplier effect on the education of the second child. At the same time, good sibling relationship can promote the generation of reciprocal and mutually beneficial behaviors, thereby strengthen imitative learning among social compatriots for socially adaptive behaviors. Therefore, parents should work hard to promote the sibling relationship through multiple efforts. In addition, children are more inclined to imitate the behavior which is rewarded, and do not imitate the behavior which is punished. Therefore, parents should promptly encourage and praise children for their correct behavior and criticize the wrong behavior. They must not be confused and shake the education principle. Education behaviors based on principles can help children built indirectly experience and establish correct understanding by observing and learning, even if they do not directly experience corresponding events, so that the social learning mechanism can fully play its positive role. 
C. Equity and fairness, Promoting a virtuous cycle of social comparing

For siblings, social comparison is inevitable. What parents should do is try to avoid the negative effects and enhance positive effects brought by social comparisons. Since an important content of competition among children is the attention of parents, the behavior or characteristics that the other person can draw attention from their parents will become the content of sibling comparisons. Parents can use this mechanism, giving more warm attention to behaviors that help children develop good habits and form a sound personality, thus helping children develop a good habits. However, it is worth noting that, before this, parents must establish the right concept of value, which behaviors are beneficial to the physical and mental development of children and need to be maintained, and which behaviors will cause adverse effects and need to be forbidden, so as to bring children the right guidance. In this process, parents should try their best to be fair and impartial, and avoid making children think that "parents prefer a certain party and they don't pay attention no matter how hard I am". At the same time, parents should pay attention to children's ideological changes in a timely manner to prevent children from negatively evaluating themselves because so excellent their siblings are. Regarding the children's unrelated good or bad characteristics, parents should give a fair assessment to help children establish a correct understanding of their uniqueness, and do not make children lose their self because of blind comparisons.

\section{CONCLUSION}

In short, with the development of society, people are increasingly aware of the important role of the scientific nature of family education methods in the development of children's physical and mental health. This paper analyzes the current status and existing problems of the two-child families, and puts forward corresponding suggestions based on the mechanism of the sibling relationship. However, at present, there is still a lot of gaps in the understanding of the psychological development process and the laws of interaction between siblings, and there is also a lack of scientific and systematic knowledge about how to educate the two children. Therefore, a large number of scholars are required to continue to explore and contribute to the two-child family education theory, thus strengthen the correctness of parental rearing styles and promoting the development of children's physical and mental health.

\section{REFERENCES}

[1] CHEN Bin-Bin, WANG Yan, LIANG Ji, TONG Lian. (2016). And baby makes four: Biological and psychological changes and influential factors of firstborn's adjustment to transition to siblinghood [J]. Advances in Psychological Science ,24(06):863-873. (In Chinese)

[2] ZHAO Shi-ying, HONG Xiao-nan. (2001). The Dialectical Relationship between Explicit Knowledge and Tacit Knowledge [J]. Studies in Dialectics of Nature, (10):20-23+33. (In Chinese)

[3] ZHANG Jin-Feng. (2005). A New Philosophic Idea of the Importance of Family Education [J]. Theory and Practice of Education, (01):52-57. (In Chinese)

[4] CHEN Bin-Bin, ZHAO Yu, HAN Wen.et al. (2017). Sibling relationships: Forms, causes and consequences [J]. Advances in Psychological Science, 25(12):2168-2178. (In Chinese)

[5] Kim, J.-Y., McHale, S. M., Crouter, A. C., \& Osgood, D. W. (2007) Longitudinal linkages between sibling relationships and adjustment from middle childhood through adolescence. Developmental Psychology, 43, 960-973.

[6] Harper, J. M., Padilla-Walker, L. M., \& Jensen, A. C. (2016). Do siblings matter independent of both parents and friends? Sympathy as a mediator between sibling relationship quality and adolescent outcomes. Journal of Research on Adolescence, 26, 101-114.

[7] Fraley, R. C., \& Tancredy, C. M. (2012). Twin and sibling attachment in a nationally representative sample. Personality and Social Psychology Bulletin, 38, 308-316.

[8] Graham, A. A., \& Coplan, R. J. (2012). Shyness, sibling relationships, and young children's socioemotional adjustment at preschool. Journal of Research in Childhood Education, 26, 435-449.

[9] Bandura, A. (1977). Social learning theory. Englewood Cliffs, NJ: Prentice Hall.

[10] Kramer, L. (2014). Learning emotional understanding and emotion regulation through sibling interaction. Early Education and Development, 25, 160-184.

[11] Noller, P. (2005). Sibling relationships in adolescence: Learning and growing together. Personal Relationships, 12, 1-22.

[12] [McHale, S. M., Updegraff, K. A., Jackson-Newsom, J., Tucker, C. J., \& Crouter, A. C. (2000). When does parents' differential treatment have negative implications for siblings? Social Development, 9, 149-172. 